\title{
СРАВНИТЕЛЬНО-ПРАВОВАЯ ХАРАКТЕРИСТИКА ПРАКТИКИ ПРИМЕНЕНИЯ ЗАКОНОВ «О ЗАЩИТЕ ПРАВ ПОТРЕБИТЕЛЕЙ» СУДАМИ РОССИИ, УКРАИНЫ И БЕЛОРУССИИ: ОТДЕЛЬНЫЕ АСПЕКТЫ
}

Аннотация: После принятия Законов Российской Федерации, Украины, Белоруссии «О защите прав потребителей» в государствах была создана современная национальная система защиты прав потребителей, способствующая созданию гражданско-правового механизма защиты прав граждан на рынке товаров и услуг. Несмотря на то, что белорусское, российское, украинское законодательство исходит из общепризнанных международных принципов защить прав потребителей, имеет ряд схожих по своему содержанию положений, тем не менее, практика его применения имеет свою специфику, отражающую характерные для каждого правопорядка особенности гражданско-правового механизма защить прав потребителей. В статье автором использовались методы анализа, абстрагирования и сравнительного правоведения, в результате применения которых определены условия эффективности судебного правоприменения в каждом государстве. Научная новизна исследования состоит в том, что это одна из первых работ по сравнительному исследованию опыта судебного правоприменения законов России, Украины и Белоруссии. В ходе исследования автор приходит к выводам, что анализ и выработанные в настоящей статье предложения могут быть использованы при разработке научной конщепции развития гражданских правоотношений с участием потребителей, а схожесть правовых систем и опыт применения законов на практике свидетельствует об объективной возможности и перспективности взаимного заимствования отдельных правовых норм. НИР выполнена в рамках государственного задания Минобрнауки России, код проекта 2191 (Т.№1.17.14Ф).

Abstract: After enacting consumer protection laws in the Russian Federation, Ukraine, and Belarus the nations established a modern national system of protection of consumer rights, which contributed to creation of civil legal mechanism of consumer protection in the market of goods and services. Despite the fact that Belarusian, Ukrainian, and Russian legislation was based on the general international principles of consumer protection and has a number of similar in content positions, its implementation still has its own specificity that reflects the nature of each civil legal mechanism of consumer protection. In the course of this research the author comes to the conclusions that the analysis and the derived positions can be used in devising a scientific concept of development of civil legal relations with participation of consumers, and the similarity between the legal systems, as well as the experience of implementation of laws testifies to the objective possibility and opportunity for a mutual sharing of separate legal norms.

Ключевые слова: Потребитель, правоприменение, защита права, Россия, Белоруссия, Украина, законодательство, сравнительное правоведение, закон, Верховный суд.

Keywords: Consumer, law enforcement, protection of rights, Russia, Belarus, Ukraine, legislation, comparative jurisprudence, law, Supreme Court.

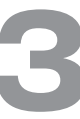

ащита прав потребителей во всем мире-одна из главнейших задач функционирования и развития экономики любого государства, чьи стратегические задачи направлены, в том числе, и на решение проблем обеспечения населения качественными жизненными благами. Неизменно и ее непосредственное влияние на поддержку социальной стабильности и национальной безопасности государства. Создание условий для эффективной реализации механизмов защиты прав потребителей «обусловливает необходимость гармонизации национальных и международной правовых систем и влечет за собой совместные усилия государства, общества и бизнеса»1.

\footnotetext{
${ }^{1}$ См.: Актуальные вопросы защиты прав потребителей в государствах - участниках СНГ (информационно-аналитический обзор). М., 2012. C. 3
}

Потребитель, несмотря на все усилия законодателя упрочить его положение на рынке товаров и услуг, находится в зависимом положении. У потребителя и предпринимателя ${ }^{2}$ разные, но взаимозависимые цели, находящиеся в одной плоскости гражданского оборота: удовлетворение личных, семейных, бытовых и иных нужд, не связанных с осуществлением предпринимательской деятельности и извлечение прибыли.

Одним из публично-правовых инструментов защиты прав потребителей, который направлен на обеспечение эффективной реализации субъективных прав потребителей, является судебная защита.

\footnotetext{
2 Под предпринимателем в настоящей работе мы понимаем контрагентов потребителей (продавец, исполнитель, изготовитель и иные субъекты, обозначенные в национальных законах).
} 
DOI: $10.7256 / 1811-9018.2014 .12 .11258$

При цитировании этой статьи сноска на doi обязательна

\section{Право и политика $12(180) \cdot 2014$}

Проблемы защиты прав потребителей в судебном порядке приобрели самостоятельное значение, т.к. во многом недостатки законодательства проявляются именно в процессе судебной защиты права. В тоже время, судебная практика реагирует на правовую жизнь общества, анализирует основные проблемы и формирует «универсальные» ответы на наиболее типичные правовые ситуации.

Россия, Белоруссия и Украина - государства со сложившимися национальными системами защиты прав потребителей. В результате принятия Законов о защите прав потребителей (Закон РФ от 07 февраля 1992 г. № 2300-1 (далее - Закон России), Закон Украины от 12 мая 1991 г. № 1023-XII (далее - Закон Украины), Закон Республики Беларусь от 09 января 2002 г. № 90-3 (далее - Закон Белоруссии)) была создана правовая основа для формирования и реализации целенаправленной государственной политики области защиты прав граждан в сфере торговли и услуг.

Национальная политика в сфере защиты прав потребителей трех государств основывается на Конституции, Гражданском кодексе ${ }^{3}$, Законах «О защите прав потребителей», законах и иных нормативно- правовых актах, регулирующих отношения в области защиты прав потребителей. В Украине государственная защита прав потребителей опирается на Конституцию: государство защищает права потребителей, осуществляет контроль за качеством и безопасностью товаров и всех видов услуг и работ, способствует деятельности общественных организаций потребителей (ст. 42). В Белоруссии, наряду с Законом Белоруссии, действует самостоятельный Закон «О защите прав потребителей жилищно-коммунальных услуг».

Судебная защита прав потребителей осуществляется на основании ст. 17 Закона России, ст. 44 Закона Белоруссии, ст. 22 Закона Украины, а также соответствующих положений гражданско-процессуальных кодексов. В целях правильного и единообразного применения законодательства о защите прав потребителей в трех государствах были приняты специальные Постановления Пленумов Верховных Судов: Постановление Пленума Верховного суда Украины от 12 апреля 1996 г № 5 «О практике рассмотрения гражданских дел по искам о защите прав потребителей» (далее Постановление 5), Постановление Пленума Верховного Суда Республики Беларусь от 24 июня 2010 г. № 4 «О практике применения судами законодательства при рассмотрении дел о защите прав потребителей» (далее-Постановление 4), Постановление Пленума Верховного Суда РФ от 28 июня 2012 г. № 17 «О рассмотрении судами гражданских дел по спорам о защите прав потребителей» (далее - Постановление 17).

Заслугой белорусского правоприменителя является прямое указание в Постановлении 4 на то, что данное законодательство не распространяется на отношения, возникшие в связи с приобретением товаров для предпринимательской деятельности, а также на отношения по приобретению товаров, выполнению работ и оказанию услуг для нужд организаций (п. 2). В Законе Украины на законодательном уровне закреплено положение, согласно которому субъекты предпринимательской деятельности (юридические лица,

\footnotetext{
${ }^{3}$ В Украине наряду с Гражданским кодексом действует Хозяйственный кодекс Украины, который также включен в систему законодательства о защите прав потребителей.
}

индивидуальные предприниматели), не могут использовать для защиты прав дополнительные гарантии, предоставленные потребителям. В России в связи с неопределенностью данного вопроса, широко развиты дискуссии относительно возможности распространения норм Закона России и на юридических лиц ${ }^{4}$, а судебное толкование Закона России позволяет распространять его положения на индивидуальных предпринимателей (п. 17 Постановления 17).

Подходы к процессуальным особенностям судебной защиты прав потребителей в исследуемых Постановлениях различны. По нашему мнению, механизм гражданско-процессуальной защиты прав потребителей, заложенный в Законе России и отраженный в Постановлении 17, в большей степени отвечает интересам потребителей.

Так, Законы Белоруссии и Украины не содержат специального указания на альтернативную подсудность по данной категории дел. Между тем, установление альтернативной подсудности во многом облегчает потребителю путь по осуществлению защиты своих прав, и вытекает из «компенсационного» характера экономического неравенства сторон рассматриваемых правоотношений.

В Белоруссии и Украине определяется Гражданскопроцессуальным кодексом (ст. 46, ч.12 ст.47, ст. 49 ГПК Белоруссии; п. 5 ст. 110 ГПК Украины). Это свидетельствует о том, что так называемое «условие о договорной подсудности» не является нарушением прав потребителей в этих странах, что ущемляет права потребителя как слабой стороны в правоотношении.

В России, несмотря на установление альтернативной подсудности (ст. 17 Закона), получила распространение проблема, связанная с включением в договор с участием потребителей оговорок о подсудности ${ }^{5}$. По нашему мнению, данная проблема возникла в связи с неопределенностью формулировки ст. 16 Закона России «Недействительность условий договора, ущемляющих права потребителя». Исходя из содержания статьи, не усматривается, являются ли такие условия ничтожными или оспоримыми. В Законе Украины устанавливается открытый перечень несправедливых условий договора. Толкование ст. 18 Закона Украины дает основание полагать, что перечисленные в ней несправедливые условия договора, противоречащие принципу справедливости, являются оспоримыми. В этой связи наиболее удачным представляется содержание ст. 19 Закона Белоруссии, устанавливающей ничтожность договорных условий, ограничивающих права потребителей по сравнению с действующим законодательством.

По разному подходят судебные инстанции России, Белоруссии и Украины к вопросу о размерах взыскиваемых

\footnotetext{
${ }^{4}$ См.: Бельх В.С. Правовое регулирование предпринимательской деятельности. М., 2010. 423 с; Данилов В.В. Защита прав потребителя в системе конституционных прав человека в России. Автореф. ... канд. юрид. наук. М., 2009. 26 с; Кирюшина И.В. Правовой статус потребителя и его реализация в гражданском праве. Дис. ... канд. юрид. наук. Барнаул, 2004. 215 с; Корнилов Э. Юридическое лицо как потребитель // Закон. 1999. № 3. С. 120-123.

${ }^{5}$ См.: Гурылев Б. Договорная подсудность: свобода воли или ущемление прав потребителей // Юридическая газета. 2011. № 12. / СПС «КонсультантПлюс»: поиск по автору; Лейбошиц А.В. Актуальные проблемы гражданского процесса: договорная подсудность по делам с участием потребителей // Вестник Московского университета. Серия 11. Право. 2011. № 5. С. 135-147.
} 
DOI: $10.7256 / 1811-9018.2014 .12 .11258$

При цитировании этой статьи сноска на dоі обязательна

Юридический практикум

неустоек. Размеры неустойки, предусмотренные законами трех государств и взыскиваемые с продавца (исполнителя, изготовителя) за неисполнение требований потребителя, не совпадают только в Белоруссии: $1 \%$ от стоимости товара за каждый день просрочки в случае неисполнения требований в отношении товаров (Россия, Белоруссия, Украина), 3 \% (Россия, Украина) и 1\% (Белоруссия) от стоимости работ (услуг), а если она не определена, то от общей цены заказа - в отношении работ (услуг).

Вопрос о размере взыскиваемой неустойки представляет собой значительный практический интерес. Законы Белоруссии и Украины не содержат указания на ограничение размера неустойки ценой выполненной работы (оказанной услуги), в то время как Закон России предусмотрено такое ограничение (п.5 ст. 28). В части взыскания неустойки Постановление 17 разъяснило, что применение статьи 333 ГК РФ по делам о защите прав потребителей возможно в исключительных случаях и по заявлению ответчика с обязательным указанием мотивов, по которым суд полагает, что уменьшение размера неустойки является допустимым (п.34), что значительно повышает эффективность данного способа защиты прав потребителей. В Постановлении 4 каких-либо особенностей в части взыскания неустойки не предусматривается, напротив, к ней применяются общие правила ГК Белоруссии о праве суда снизить ее размер, если она явно не соразмерна последствиям нарушенного обязательства (п.22). Постановление 5 не только допускает взыскание неустойки, но и в значительной степени снижает ее эффективность как способа защиты прав потребителей, поскольку учитывает при ее определении слишком высокий размер по сравнению с убытками потребителя, степень выполнения обязательства, имущественное положение сторон, их имущественные и другие интересы, заслуживающие внимания (п.22).

Российские, белорусские и украинские потребители имеют право на компенсацию морального вреда в силу прямого указания законов (ст. 15 , ст. 18 , ст. 4 соответственно). Постановление 17 установило презумпцию вины предпринимателя, указав, что для взыскания компенсации морального вреда достаточным основанием является установление факта нарушения потребителя.

Размер суммы морального вреда по российскому законодательству ограничен характером нравственных и физических страданий, причиненных потребителю (п. 45 Постановления 17), виной нарушителя (ст. 15 Закона), и возмещается с учетом требований разумности и справедливости (п. 2 ст. 1101 ГК РФ). Ст. 18 Закона Белоруссии добавляет, что характер нравственных и физических страданий, оценивается судом с учетом фактических обстоятельств и индиви- дуальных особенностей потребителя, а Постановлении 4 добавлено весьма важное разъяснение: размер компенсации зависит также от поведения предпринимателя при предъявлении к нему требований об устранении допущенных нарушений. Кроме того, в Постановлении 4, хотя и закрепляется презумпция вины предпринимателя, допускается возможность доказывания отсутствия вины причинителя вреда, что, на наш взгляд, отвечает принципу добросовестности и справедливости.

Все же реализация компенсации морального вреда как способа защиты прав потребителей в судебной практике России и Белоруссии более эффективна, чем в Украине: в подп.5 п.1. ст.4 Закона Украины «О защите прав потребителей» установлено, что потребитель имеет право на возмещение имущественного и морального вреда, причиненного вследствие недостатков продукции (дефекта в продукции) в соответствии с законом. Это означает, что компенсация морального вреда по Закону Украины возможна не при любом нарушении прав потребителей (например, нарушении сроков выполнения работ, нарушения права на информацию), а только если имущественный вред был причинен вследствие недостатков продукции. Это подтверждает и п. 2 ст. 22 Закона Украины «Судебная защита прав потребителей»: при удовлетворении требования потребителя суд одновременно решает вопрос о возмещении морального (неимущественного) вреда.

Сравнительно-правовые исследования в области защиты прав потребителей в странах ближнего зарубежья наглядно высвечивают недостатки национальных механизмов защиты прав потребителей. Опыт проведения таких исследований, особенно в сочетании с изучением судебной практики, во многом способствует совершенствованию законодательства о защите прав потребителей. Эффективность реализации этого механизма напрямую зависит не только от содержания норм закона, но и от правильного и единообразного их применение. В этом направлении усилия высших судов России, Белоруссии и Украины выражены в принятии соответствующих Постановлений Пленумов. Сравнительно-правовой анализ показал, что, несмотря на общий подход, выраженный в Постановлениях, отдельные элементы механизма значительно ослабляют его общую действенность. Полагаем, что наличие объективной возможности и перспективности взаимного заимствования отдельных правовых норм и их восприятия, выраженного в судебном толковании, будет способствовать не только повышению уровня защиты прав потребителей, но стать новым этапом развития правоотношений с участием потребителей в России, Белоруссии и Украине, в которых устраняется правовое неравенство участников потребительского рынка, присутствует разумный баланс интересов, и обеспечивается приоритет интересов потребителей.

\section{Библиография:}

1. Белых В.С. Правовое регулирование предпринимательской деятельности. - М., 2010. - 423 с.

2. Гурылев Б. Договорная подсудность: свобода воли или ущемление прав потребителей // Юридическая газета. - 2011. - № 12. / СПС «КонсультантПлюс»: поиск по автору.

3. Данилов В.В. Защита прав потребителя в системе конституционных прав человека в России. Автореф. ... канд. юрид. наук. - М., 2009. $-26 \mathrm{c}$.

4. Кирюшина И.В. Правовой статус потребителя и его реализация в гражданском праве. Дис. ... канд. юрид. наук. - Барнаул, 2004. - 215 c.

5. Корнилов Э. Юридическое лицо как потребитель // Закон. - 1999. - № 3. - С. 120-123.

6. Лейбошиц А.В. Актуальные проблемы гражданского процесса: договорная подсудность по делам с участием потребителей // Вестник Московского университета. Серия 11. Право. - 2011. - № 5. - С. 135-147. 
DOI: $10.7256 / 1811-9018.2014 .12 .11258$

При цитировании этой статьи сноска на доі обязательна

\section{Право и политика $12(180) \cdot 2014$}

7. Михайлов Д.И. Договор возмездного оказания услуг: вопросы повышения уровня защиты прав потребителей // Юридический журнал. - 2009. - № 4. - С. 14-18.

8. Фурса С.Я., Кармаза О.О. Основи споживчих знань. Захист прав споживачів: судова та адвокатська практика. - Кіев, 2009. - 704 с.

9. Гуляихин В.Н. Правовой менталитет российских граждан // NB: Вопросы права и политики. - 2012. - 4. - C. 108-133. URL: http:// www.e-notabene.ru/lr/article_310.html

10. Каминская Н.В., Букач В.В., Билас И.Г. Юридическое содержание конституционного права на обращение в контексте Конституции Российской Федерации и Конституции Украины // Право и политика. - 2013. - 13. - C. 1825-1830. DOI: 10.7256/1811-9018.2013.13.9817.

11. Лобанов С.А.. Административно-правовое регулирование торговой деятельности в системе потребительского рынка // Административное и муниципальное право. - 2012. - № 8. - С. 104-107.

12. Н. В. Паранчева, Н. А. Ефремова. Особенности применения законодательства о защите прав потребителей // Право и политика. - 2012. - № 9. - C. 104-107.

13. Лобанов С.А.. Проблемы взаимодействия юрисдикционных органов в сфере потребительского рынка // Полицейская деятельность. 2012. - № 3. - С. 104-107.

14. Костенников М.В., Лобанов С.А.. Административно-юрисдикционная защита прав потребителей // Административное и муниципальное право. - 2012. - № 5. - С. 104-107.

15. Лобанов С.А.. Нормы административного права в юрисдикционной деятельности органов внутренних дел в сфере потребительского рынка // Административное и муниципальное право. - 2012. - № 4. - С. 104-107.

16. Лобанов С.А.. Проблемы квалификации административных правонарушений в сфере потребительского рынка // Полицейская деятельность. - 2012. - № 1. - С. 104-107.

17. Ланина Е.Ю.. Административно-правовое обеспечение органами внутренних дел правопорядка в сфере потребительского рынка. // Административное и муниципальное право. - 2010. - № 11. - С. 104-107.

18. Е. А. Котова. Актуальные вопросы торговой деятельности (торговли) как объекта гражданско-правового регулирования. // Право и политика. - 2010. - № 10.

19. Боголюбский С.С.. К вопросу о генезисе виктимного, возникающего при осуществлении предпринимательской деятельности // Административное и муниципальное право. - 2013. - № 3. - С. 104-107. DOI: 10.7256/1999-2807.2013.03.8.

20. А. А. Бурцева. Социальная предпринимательская деятельность некоммерческих организаций в России как объект правового регулирования // Право и политика. - 2012. - № 8. - С. 104-107.

21. К. В. Моисеев. Малое предпринимательство в России и за рубежом // Политика и Общество. - 2012. - № 7. - С. 104-107.

22. Тарасова Т.В.. Понятие стандарта потребительского поведения в рыночной экономике // Политика и Общество. - 2013. - № 7. C. 104-107. DOI: 10.7256/1812-8696.2013.7.9107.

23. Лобанов С.А.. К вопросу о понятии и содержании административной юрисдикции в сфере потребительского рынка. // Полицейская деятельность. - 2012. - № 2. - С. 104-107

\section{References (transliterated):}

1. Belykh V.S. Pravovoe regulirovanie predprinimatel'skoi deyatel'nosti. - M., 2010. - $423 \mathrm{~s}$.

2. Gurylev B. Dogovornaya podsudnost': svoboda voli ili ushchemlenie prav potrebitelei // Yuridicheskaya gazeta. - 2011. - № 12. / SPS «Konsul'tantPlyus»: poisk po avtoru.

3. Danilov V.V. Zashchita prav potrebitelya v sisteme konstitutsionnykh prav cheloveka v Rossii. Avtoref. ... kand. yurid. nauk. - M., 2009. - 26 s.

4. Kiryushina I.V. Pravovoi status potrebitelya i ego realizatsiya v grazhdanskom prave. Dis. ... kand. yurid. nauk. - Barnaul, 2004. - 215 s.

5. Kornilov E. Yuridicheskoe litso kak potrebitel' // Zakon. - 1999. - № 3. - S. 120-123.

6. Leiboshits A.V. Aktual'nye problemy grazhdanskogo protsessa: dogovornaya podsudnost' po delam s uchastiem potrebitelei// Vestnik Moskovskogo universiteta. Seriya 11. Pravo. - 2011. - № 5. - S. 135-147.

7. Mikhailov D.I. Dogovor vozmezdnogo okazaniya uslug: voprosy povysheniya urovnya zashchity prav potrebitelei // Yuridicheskii zhurnal. 2009. - № 4. - S. 14-18.

8. Fursa S.Ya., Karmaza O.O. Osnovi spozhivchikh znan'. Zakhist prav spozhivachiv: sudova ta advokats'ka praktika. - Kiev, 2009. - 704 s.

9. Gulyaikhin V.N. Pravovoi mentalitet rossiiskikh grazhdan // NB: Voprosy prava i politiki. -2012. - 4. - C. 108-133. URL: http://www.e-notabene. $\mathrm{ru} / \mathrm{lr} /$ article $310 . \mathrm{html}$

10. Kaminskaya N.V., Bukach V.V., Bilas I.G. Yuridicheskoe soderzhanie konstitutsionnogo prava na obrashchenie v kontekste Konstitutsii Rossiiskoi Federatsii i Konstitutsii Ukrainy // Pravo i politika. - 2013. - 13. - C. 1825-1830. DOI: 10.7256/1811-9018.2013.13.9817.

11. Lobanov S.A.. Administrativno-pravovoe regulirovanie torgovoi deyatel'nosti v sisteme potrebitel'skogo rynka // Administrativnoe i munitsipal'noe pravo. - 2012. - № 8. - S. 104-107.

12. N. V. Parancheva, N. A. Efremova. Osobennosti primeneniya zakonodatel'stva o zashchite prav potrebitelei // Pravo i politika. - 2012. - № 9. - S. 104-107.

13. Lobanov S.A.. Problemy vzaimodeistviya yurisdiktsionnykh organov v sfere potrebitel'skogo rynka // Politseiskaya deyatel'nost'. - 2012. № 3. - S. 104-107.

14. Kostennikov M.V., Lobanov S.A.. Administrativno-yurisdiktsionnaya zashchita prav potrebitelei // Administrativnoe i munitsipal'noe pravo. - 2012. - № 5. - S. 104-107.

15. Lobanov S.A.. Normy administrativnogo prava v yurisdiktsionnoi deyatel'nosti organov vnutrennikh del $\mathrm{v}$ sfere potrebitel'skogo rynka // Administrativnoe i munitsipal'noe pravo. - 2012. - № 4. - S. 104-107.

16. Lobanov S.A.. Problemy kvalifikatsii administrativnykh pravonarushenii v sfere potrebitel'skogo rynka // Politseiskaya deyatel'nost'. - 2012. - № 1. - S. 104-107.

17. Lanina E.Yu.. Administrativno-pravovoe obespechenie organami vnutrennikh del pravoporyadka v sfere potrebitel'skogo rynka.// Administrativnoe i munitsipal'noe pravo. - 2010. - № 11. - S. 104-107.

18. E. A. Kotova. Aktual'nye voprosy torgovoi deyatel'nosti (torgovli) kak ob"ekta grazhdansko-pravovogo regulirovaniya. // Pravo i politika. 2010. - № 10.

19. Bogolyubskii S.S.. K voprosu o genezise viktimnogo, voznikayushchego pri osushchestvlenii predprinimatel'skoi deyatel'nosti // Administrativnoe i munitsipal'noe pravo. - 2013. - № 3. - S. 104-107. DOI: 10.7256/1999-2807.2013.03.8. 
DOI: $10.7256 / 1811-9018.2014 .12 .11258$

При цитировании этой статьи сноска на доі обязательна

Юридический практикум

20. A. A. Burtseva. Sotsial'naya predprinimatel'skaya deyatel'nost' nekommercheskikh organizatsii v Rossii kak ob"ekt pravovogo regulirovaniya // Pravo i politika. - 2012. - № 8. - S. 104-107.

21. K. V. Moiseev. Maloe predprinimatel'stvo v Rossii i za rubezhom // Politika i Obshchestvo. - 2012. - № 7. - S. 104-107.

22. Tarasova T.V.. Ponyatie standarta potrebitel’skogo povedeniya v rynochnoi ekonomike // Politika i Obshchestvo. - 2013. - № 7. - S. 104-107. DOI: $10.7256 / 1812-8696.2013 .7 .9107$.

23. Lobanov S.A.. K voprosu o ponyatii i soderzhanii administrativnoi yurisdiktsii v sfere potrebitel'skogo rynka. // Politseiskaya deyatel'nost'. 2012. - № 2. - S. 104-107 